\title{
A REMARK FOR SPATIAL ANALYTICITY AROUND STRAINING FLOWS
}

\author{
SEIYA HATTORI AND OKIHIRO SAWADA
}

Abstract. Time-local existence of unique smooth solutions to the Navier-Stokes equations in the whole space with linearly growing initial data has been established, via smoothing properties of Ornstein-Uhlenbeck semigroup. It has also been shown that the solution is real-analytic in spatial variables around rotating flows. This note is devoted to prove the spatial analyticity for cases of straining flows and shear flows. It is estimated the size of radius of convergence of Taylor series, due to estimates for higher order derivatives and Cauchy-Hadamard theorem.

Mathematics subject classification (2010): 35Q30, 76U05, 76F10.

Keywords and phrases: Navier-Stokes equations, Ornstein-Uhlenbeck semigroup, straining flows, spatial analyticity.

\section{REFERENCES}

[1] W. BorCHERS, Zur Stabilität und Faktorisierungsmethode für die Navier-Stokes Gleichungen inkompressibler viskoser Flüssigkeiten, Habilitationsschrift, Universität Paderborn, 1992.

[2] J. R. CANnON And G. H. KNIGHTLY, A note on the Cauchy problem for the Navier-Stokes equations, SIAM J. Appl. Math., 18, (1970), 641-644.

[3] M. Cannone, Ondelettes, paraproduits et Navier-Stokes, (French) With a preface by Yves Meyer. Diderot Editeur, Paris, 1995.

[4] Z.-M. Chen And T. MiyakAwa, Decay properties of weak solutions to a parturbed Navier-Stokes system in $\mathbb{R}^{n}$, Adv. Math. Sci. Appl., 7, (1997), 741-770.

[5] H. Fujita And T. Kato, On the Navier-Stokes initial value problem I, Arch. Rational Mech. Anal., 16, (1964), 269-315.

[6] Y. GigA, Solutions for semilinear parabolic equations in $L^{p}$ and regularity of weak solutions of the Navier-Stokes system, J. Differential Equations, 62, 2 (1986), 186-212.

[7] Y. Giga, M. Gries, M. Hieber, A. Hussein And T. KAshiwaBARA, Analyticity of solutions to the primitive equations, (preprint).

[8] Y. Giga, K. Inui And S. Matsui, On the Cauchy problem for the Navier-Stokes equations with nondecaying initial data, Advances in fluid dynamics, 27-68, Quad. Mat., 4, Dept. Math., Seconda Univ. Napoli, Caserta, 1999.

[9] Y. Giga And T. MiYaKaWA, Solutions in $L^{r}$ of the Navier-Stokes initial value problem, Arch. Rational Mech. Anal., 89, (1985), 267-281.

[10] Y. GIGA AND O. SAWADA, On regularizing-decay rate estimates for solutions to the Navier-Stokes initial value problem, Nonlinear analysis and applications: to V. Lakshmikantham on his 80th birthday. Vol. 1, 2, 549-562, Kluwer Acad. Publ., Dordrecht, 2003.

[11] M. HIEBER, A. RHANDIAND O. SAWADA, The Navier-Stokes flow for globally Lipschitz continuous initial data, Kyoto Conference on the Navier-Stokes Equations and their Applications, 159-165, RIMS Kôkyûroku Bessatsu, B1, Res. Inst. Math. Sci. (RIMS), Kyoto, 2007.

[12] M. Hieber AND O. SAWADA, The Navier-Stokes equations in $\mathbb{R}^{n}$ with linearly growing initial data, Arch. Rational Mech. Anal., 175, 2 (2005), 269-285.

[13] C. Kahane, On the spatial analyticity of solutions of the Navier-Stokes equations, Arch. Rational Mech. Anal., 33, (1969), 386-405.

[14] T. KATO, Strong $L^{p}$-solutions of Navier-Stokes equations in $\mathbf{R}^{m}$ with applications to weak solutions, Math. Z., 187, (1984), 471-480. 
[15] H. Koch AND D. TAtARU, Well-posedness for the Navier-Stokes equations, Adv. Math., 157, 1 (2001), 22-35.

[16] J. LERAY, Sur le mouvement d'un liquide visqueux emplissant l'espace, (French) Acta Math., 63, 1 (1934), 193-248.

[17] K. MASUdA, On the analyticity and the unique continuation theorem for solutions of the NavierStokes equation, Proc. Japan Acad., 43, (1967), 827-832.

[18] K. MASUDA, On the regularity of solutions of the nonstationary Navier-Stokes equations, In 'Approximation Methods for Navier-Stokes Problem', 360-370, Lecture Notes in Math., 771, Springer, Berlin, 1980.

[19] G. Metafune, J. Prüss, A. Rhandi And R. Schnaubelt, The domain of the OrnsteinUhlenbeck operator on an $L^{p}$-space with invariant measure, Ann. Sc. Norm. Super. Pisa Cl. Sci., 1, (2002), 471-485.

[20] H. MIURA AND O. SAWADA, On the regularizing rate estimates of Koch-Tataru's solution to the Navier-Stokes equations, Asymptot. Anal., 49, 1-2 (2006), 1-15.

[21] O. SAWADA AND T. USUI, The Navier-Stokes equations for linearly growing velocity with nondecaying initial disturbance, Adv. Math. Sci. Appl., 19, 2 (2009), 539-564. 